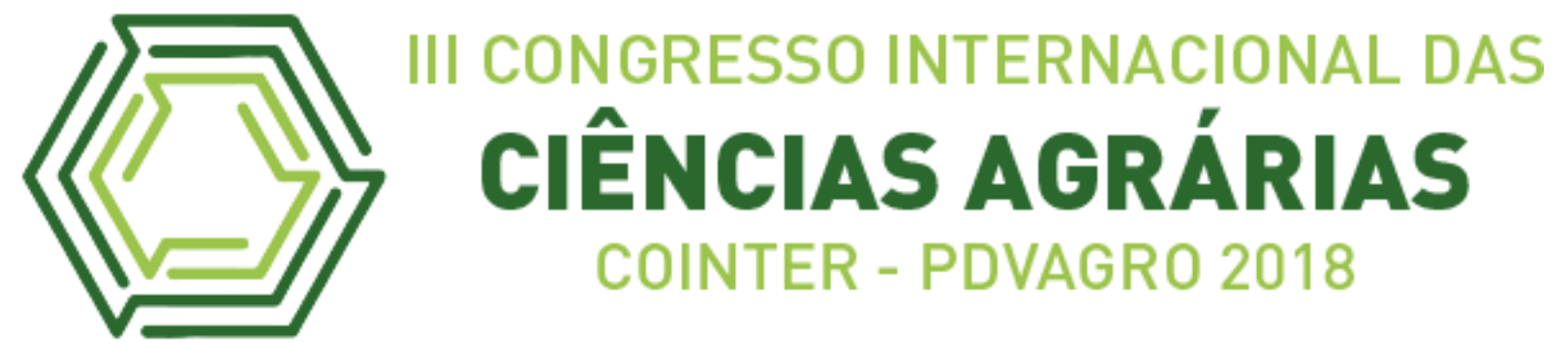

\title{
Ocorrência de cárie do sino em Panicum maximum, na fazenda agrícola do IFPA- Campus Castanhal
}

Occurrence of caries of the bell in Panicum maximum, in the agricultural farm of the IFPA-Campus Castanhal

\author{
Apresentação: Pôster \\ Gessica Jacira Trindade de Sousa ${ }^{1}$; Kamila Cristo Teixeira ${ }^{2}$; Roseane de Nazaré Pereira \\ Teixeira $^{3}$ Augusto Nazaré Cravo da Costa Junior ${ }^{4}$; Kézia Ferreira Alves ${ }^{5}$
}

\section{DOI: https://doi.org/10.31692/2526-7701.IIICOINTERPDVAGRO.2018.00786}

\section{Resumo}

A cárie do sino, Tilletia ayresii Berkeley, tem proporcionado uma redução na produção de sementes de Panicum maximum o quem tem afetado a qualidade e a produção desta forragem. A incidência deste fungo sobre esta variedade de forrageira proporciona uma queda na produtividade e na qualidade das sementes, por infectar as flores e sementes deformando-os e comprometendo seu desenvolvimento normal. $\mathrm{O}$ objetivo deste trabalho foi descrever a ocorrência de cárie do sino em P.maximum na fazenda do IFPA- Campus Castanhal. As amostras foram obtidas por meio de coleta na fazenda do instituto, as quais foram acondicionadas em sacos plásticos e transportadas ao Laboratório de Microbiologia. Foram preparadas lâminas temporárias das estruturas morfológicas do fungo para observação sob microscopia óptica. Durante a observação do fungo em laboratório, foi possível verificar a presença de conidióforos, em forma de $\mathrm{Y}$, estruturas assexuadas, com aspecto de hifas miceliais, característica do fungo Tilletia. Quando infectadas as inflorescências das forragens, apresentam as espiguetas abertas, inchadas e providas de massas de esporos acinzentadas, em substituição ao embrião da semente. No período chuvoso há aumento da incidência do fungo

\footnotetext{
${ }^{1}$ Agronomia, Instituto Federal de Educação, Ciência e Tecnologia do Pará, gesstrind@gmail.com

${ }^{2}$ Agronomia, Instituto Federal de Educação, Ciência e Tecnologia do Pará,

${ }^{3}$ Agronomia, Instituto Federal de Educação, Ciência e Tecnologia do Pará, r.e.a.nazare.sph@gmail.com

${ }^{4}$ Agronomia, Instituto Federal de Educação, Ciência e Tecnologia do Pará, Augustoifpa@gmail.com

${ }^{5}$ Professora, Instituto Federal de Educação, Ciência e Tecnologia do Pará, kezia.alves@ifpa.edu.br
} 
sobre as panículas; portanto, o agente etiológico da cárie do sino, registrada na fazenda experimental do IFPA Castanhal, acometendo panículas de $P$. maximum é Tilletia ayresii, esta enfermidade ocasiona danos irreversíveis ao banco de sementes dessa forrageira.

Palavras-Chave: Tilletia ayresii, Descrição, Doenças de pastagem.

\begin{abstract}
Bell caries, Tilletia ayresii Berkeley, has been providing a reduction in the production of Panicum maximum seeds which has affected the quality and production of this fodder. The incidence of this fungus on this variety of forage provides a fall in productivity and seed quality, by infecting the flowers and seeds deforming them and compromising their normal development. The objective of this work was to describe the occurrence of caries of the bell in P.maximum at the IFPA Campus Castanhal. The samples were obtained by means of collection on the farm of the institute, which were packed in plastic bags and transported to the Laboratory of Microbiology. Temporal slides of morphological structures of the fungus were prepared for observation under light microscopy. During the observation of the fungus in the laboratory, it was possible to verify the presence of conidiophores, in the form of Y, asexual structures, with the appearance of mycelial hyphae, characteristic of the fungus Tilletia. When the inflorescences of fodder are infected, the spikelets are open, swollen and provided with masses of gray spores, replacing the seed embryo. In the rainy season there is an increase in the incidence of the fungus on the panicles; therefore, the etiological agent of the caries of the bell, registered in the experimental farm of the IFPA Castanhal, affecting panicles of P. maximum is Tilletia ayresii, this disease causes irreversible damage to the seed bank of this forage.
\end{abstract}

Keywords: Tilletia ayresii, Description, Pasture diseases.

\title{
Introdução
}

Os primeiros exemplares de Panicum maximum Jacq. foram introduzidos no Brasil por meio dos navios negreiros da África Ocidental. A espécie é destaque no Brasil por ser uma 
forrageira altamente produtiva, de ótima qualidade e adaptada a várias regiões do país.

O capim P.maximum tem origem na África tropical, o mesmo é encontrado como capim pioneiro em solos recém-desmatado, assim como em áreas sombreadas. A partir do século XX a espécie foi introduzida em diversos países, no Brasil a cultivar colonião, desenvolvida através de parcerias com instituições brasileiras, apresentou qualidades que chamou atenção dos produtores por apresentar alta produtividade e ampla adaptabilidade (NERES, 2008).

Os fatores ambientais, assim como a disponibilidade de nutrientes no solo e o uso de sementes de boa qualidade possuem uma influência significativa no que diz respeito à produção de forrageiras, por serem fatores essenciais para o seu desenvolvimento (ABREU et al., 2006).

A produção de sementes forrageiras apresentou um intenso aumento nas últimas décadas, em função do aumento de áreas destinadas a produção de forragens bem como o interesse de pecuaristas em utilizarem sementes de alta qualidade (REIS et al., 1995)

Nos últimos anos, uma doença tem limitado a produção e a qualidade das forrageiras, principalmente, no que diz respeito às cultivares de Panicum. A cárie do sino, Tilletia ayresii Berkeley, tem proporcionado uma redução na produção de sementes de $P$. maximum nas regiões tropicais da América (EMBRAPA, 2009). A incidência deste fungo sobre esta variedade de forrageira proporciona uma queda na produtividade e na qualidade das sementes, por infectar as flores e sementes deformando-os e comprometendo seu desenvolvimento normal, comprometendo a principal aptidão requerida por uma pastagem, que vem a ser a cobertura vegetal de determinada área.

Desta forma, o presente trabalho teve como objetivo descrever a ocorrência e a sintomatologia de cárie do sino em Panicum maximum na fazenda do IFPA- Campus Castanhal.

\section{Fundamentação Teórica}

O aumento do número de áreas cultivadas com forrageiras juntamente com a intensificação do uso destas, tem como decorrências uma crescente na existência de doenças em pastagens. Doenças promotoras de perdas em produtividade e qualidade destas gramíneas, acarretando em morte da cobertura verde, e contribuindo para a degradação de solos (MACEDO, 2006). 
Dentro do aspecto nutricional, literaturas relatam o surgimento de alterações bioquímicas em forrageiras após infecção gerada por fitopatógenos, modificações estas que interferem diretamente no aspecto nutricional de pastagens, como alterações na digestibilidade e palatabilidade da matéria prima devido a redução de proteínas, aminoácidos e carboidratos solúveis (MARTINEZ, 2010).

Dentre as decorrentes doenças de importância econômica promovida por fungos em $P$. maximum podemos citar; o carvão da braquiária causado por Ustilago operta, ocasionando podridão da semente; a mancha foliar de Bipolaris maydis a qual origina necroses do tecido foliar e de acordo com Martinez (2010) inibe a formação de perfilhos, e a cárie do sino decorrente da ação de Tilletia ayresii, a qual ocasiona a podridão da semente caracterizandose pela abertura das espiguetas as quais apresentam grande densidade de massa de esporos (EMBRAPA, 2011).

\section{Metodologia}

O presente trabalho foi desenvolvido no âmbito do IFPA Campus Castanhal. O município de Castanhal possui uma extensão territorial de $1.029 \mathrm{Km}^{2}$, e localiza-se na região Nordeste do Pará situado a $70 \mathrm{Km}$ da capital Belém, com coordenadas geográficas $01^{\circ} 00^{\prime} \mathrm{e}$

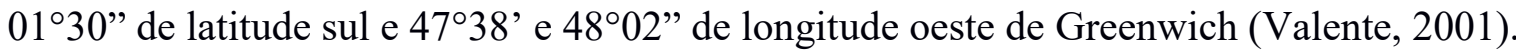

As amostras foram obtidas por meio de coleta na fazenda do instituto, as quais foram acondicionadas em sacos plásticos e transportadas ao Laboratório de Microbiologia. Foram preparadas lâminas temporárias das estruturas morfológicas do fungo para observação sob microscopia óptico

Figura 1: Panicum maximum com

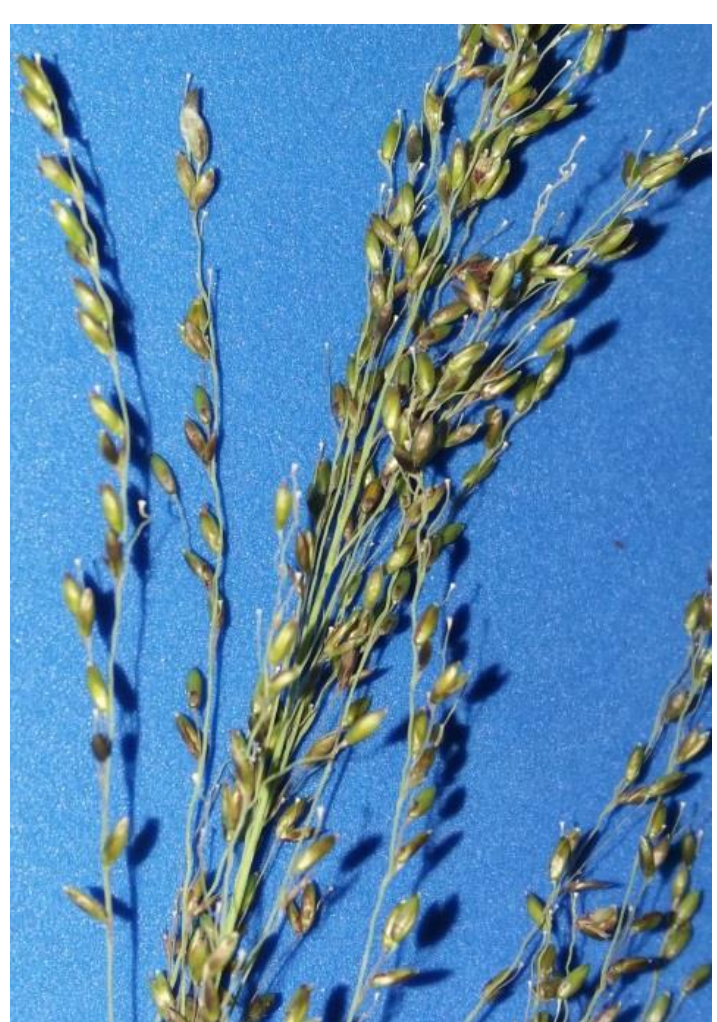
(Figura 1).

Inflorescência de intumescência fúngica 


\section{Resultados e Discussão}

O grupo filogenético Ustilagomycetes equivale à classe dos Ustilaginomycetes, baseandose em análises de pequenas subunidades de gene de RNA ribossomal, esta classe abrange dois ramos evolucionários principais: a ordem Tilletiales e Ustilaginales. Estas ordens possuem características em comum, não apresentar basidioma, apresentando somente a estrutura de soro (LUIZ, 2008).

A ordem Tilletiales (Ustilaginomycetes, Basidiomycota) apresenta seis gêneros sendo estes Conidiosporomyces, Erratomyces, Ingoldiomyces, Neovossia, Oberwinkleria e Tilletia, e conta com aproximadamente 150 espécies. Todos os gêneros constituintes da ordem Tilletiales apresentam características de hospedeiros na família Poaceae, apresentando exceção o gênero Erratomyces spp., onde o mesmo tem como hospedeiro as Fabaceae (CASTLEBURY et al., 2005).

Durante a observação do fungo em laboratório foi possível verificar a presença de teliosporos, em forma de $\mathrm{Y}$, estruturas assexuadas, com aspecto de hifas miceliais, característica do fungo Tilletia (Figura 2).

Figura 2: Estruturas assexuadas de Tilletia. A - Conidioforos bifurcados em forma de Y. B - Teliósporos globosos
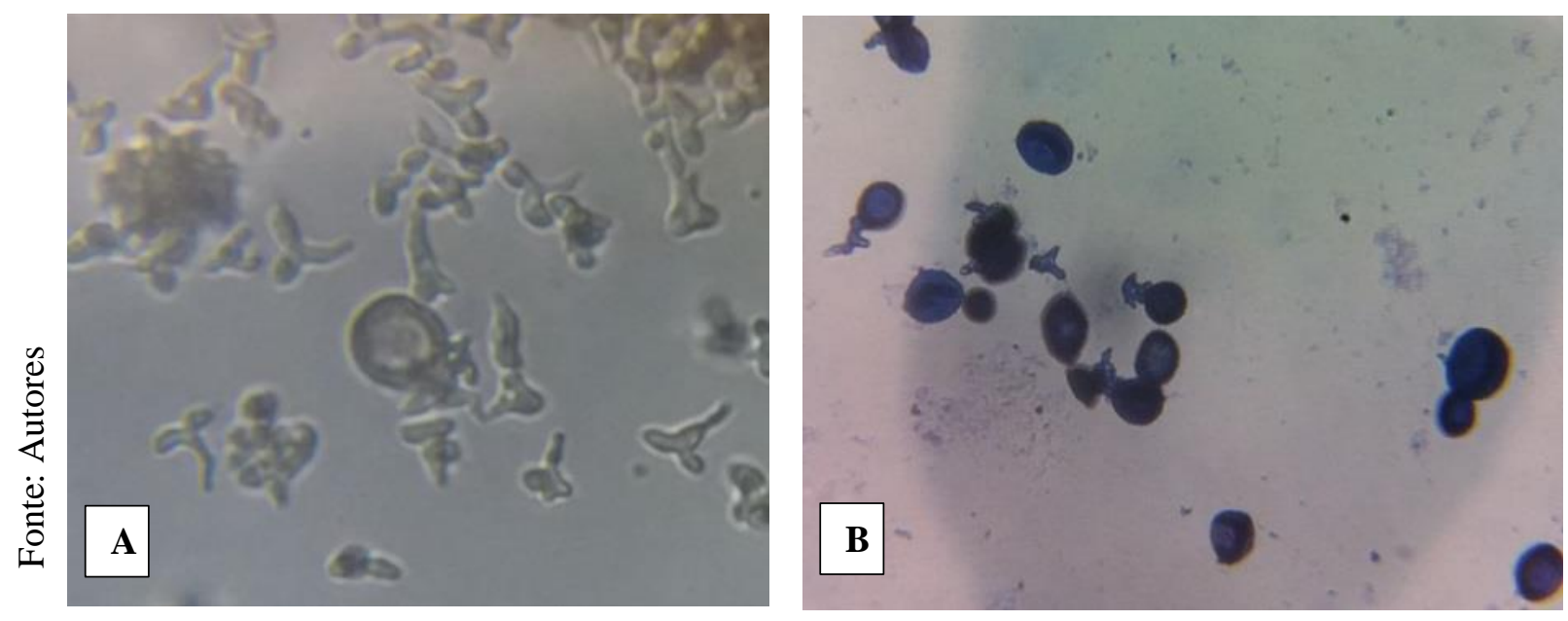
O gênero Tilletia ayresii teve sua primeira descrição feita por M. J. Berkeley das Maurícias. Foi constatado a formação de teliosporos, dentre as descrições realizadas constavam a presença de conidióforos bifurcados no esporo (em forma de Y), estruturas miceliais, com paredes finas. Os teliosporos presentes apresentavam uma forma globosa, com características de esporos inativos quando individuais fora de seu hospedeiro, apresentando coloração variando de marrom escuro a incolor (INGOLD, 1987).

Ao comparar os Blastiospores entre Tilletia ayresii e T. tritici, Ingold (1987), realizaram um ensaio de cultivo destes fungos em meio a agar, apresentando um desenvolvimento inicial de estruturas miceliais, após dois dias de cultivo não obtendo sucesso na esporulação do fungo, associou a parasita obrigatório.

Anjos et al (2009) descreve este fungo como parasita especificamente das espiguetas de $P$. maximum, no qual seus ovários formam estruturas denominadas soro, ocasionando a redução da formação de sementes.

A espécie Tilletia ayresii Berk. foi descrita pela primeira vez em Panicum maximum por M. J. Berkeley, atingindo a parte aérea e comprometendo as inflorescências das plantas. Este fungo tem como característica o parasitismo específico em espiguetas, razão pela qual a produção de sementes é substancialmente reduzida (EMBRAPA, 2009).

Quando infectadas as inflorescências das forragens, apresentam as espiguetas abertas, inchadas e providas de massas de esporos acinzentadas, em substituição ao embrião da semente (EMBRAPA, 2011). Fato este recorrente no campo de produção da fazenda experimental do IFPA-Castanhal.

Este fungo é responsável pela doença denominada de cárie do sino e está presente no Estado do Pará. Em estudos de introdução de P. maximum em Marabá, Azevedo (1982), pôde observar ataques severos do fungo durante a maturação das sementes.

O período de incidência do fungo, segundo observações do estudo vem a ser o chuvoso, o qual ocorre entre os meses de dezembro a maio, períodos com maiores índices pluviométricos do ano. Fato este observado por Santos et al. (2015), ao avaliar os genótipos de $P$. maximum a cárie do sino e a mancha foliar, observaram que a incidência da cárie do sino varia de acordo com o genótipo da planta e sob as condições de temperatura entre $16^{\circ}$ a $24^{\circ} \mathrm{C}$ e umidade entre 64 e $88 \%$.

Segundo a classificação de Koppen, o município de Castanhal, dispõe de um clima do 
tipo Af, apresentando precipitação pluviométrica média anual de 2000 a $2500 \mathrm{~mm}$, onde os maiores índices chuvosos ocorrem entre dezembro a maio; enquanto que o mais seco apresenta-se nos meses de junho a novembro. A temperatura média do município varia entre $24,7^{\circ}$ a $27,3^{\circ} \mathrm{C}$, com mínima entre $19,2^{\circ}$ a $24,2^{\circ} \mathrm{C}$ e máxima variando de $30,1^{\circ}$ a $32,7^{\circ} \mathrm{C}$. Enquanto que a umidade relativa do ar possui valores médios anuais entre 78 a 90\%, condições estas propícias ao desenvolvimento de Tilletia ayresii nas inflorescências de $P$. maximum (MARTORANO; PEREIRA, 1993).

\section{Conclusões}

O agente etiológico Tilletia ayresii foi registrada na fazenda experimental do IFPA Castanhal, acometendo panículas de Panicum maximum durante o período chuvoso da região intercalando de ano a ano entre os meses de dezembro à março. Esta enfermidade ocasiona danos irreversíveis ao banco de sementes dessa forrageira, inviabilizando o teor germinativo destes propágulos.

\section{Referências}

AZEVEDO. G. C. P. de; Introdução e avaliação de forrageiras no município de MarabáPA, Belém, EMBRAPA-CPATU, 1982.

CASTLEBURY, L. A; CARRIS, L. M. VANKY, K. phylogenetio analysis of Tilletia and alleid genera in order Tilletiales (Ustilaginomycetes; exobasidiomycetidae) based on large subnit nuclear rDNA sequences. Micologia, v. 97, p. 888-900, 2005.

EMBRAPA. Avaliação da resistência genética de genótipos de Panicum maximum ao fungo Tilletia ayresii. Boletim de pesquisa e desenvolvimento. Maio, 2009.

EMBRAPA. Doenças em Plantas forrageiras. Documentos. Dezembro, 2011.

INGOLD, C. T. Ballistospores and blastic conidia of Tilletia ayresii, and comparision with those of T. tritici and antyloma ficariae. Trans. Br. mycol. Soc. 88(1), 75-82. 1987.

JANK, L. A história do Panicum maximum no Brasil. Revista JC Maschietto, ano 01, n 01, agosto de 2003.

LUIZ, W. C. da. Micologia avançada, vol. I (taxonomia de Basidiomicetos). editora: revisao anual de patologia de plantas. 2008. 
MACEDO, M. C. M. Aspectos edáficos relacionados com a produção de Brachiaria brizantha cultivar Marandu. In: BARBOSA, R. A. (Org.). Morte de pastos de braquiárias. Campo Grande, MS: Embrapa Gado de Corte, 2006. p. 36-65.

MARTINEZ, A. da S.; FRANZENER, G.; STANGARLIN, J. R. Damages caused by Bipolaris maydis in Panicum maximum cv. Tanzânia. Semina: Ciências Agrárias, v. 31, n. 4, p. 863-870, 2010.

MARTORANO, L, G; PEREIRA, L. Estudos climáticos do Estado do Pará. Dissertação de mestrado/ universidade Federal do Pará, Belém, 126p. 1993.

NERES, M. A; MESQUITA, E. E. OLIVEIRA, P. S. R. OLIVEIRA, E. Características estruturais de cultivares de Panicum maximum Jacq. em função da adubação nitrogenada. Scientia Agraria Paranaenses. V. 7, N. 1-2 (2008).

VALENTE, MOACIR AZEVEDO et al. Solos e avaliação da aptidão agrícola das terras do município de Castanhal, Estado do Pará. Embrapa Amazônia Oriental-Documentos (INFOTECA-E), 2001. 